\title{
Primer santral sinir sistemi lenfomaları: 10 vakanın retrospektif analizi
}

\author{
Primary central nervous system lymphomas: retrospective analysis of 10 cases
}

Ayşegül Özdemir Ovalıoğlu, Gökhan Canaz, Abdullah Emre Taçyıldız, Mustafa Levent Uysal, Talat Cem Ovalığlu

\section{Özet}

Amaç: Non-Hodgkin lenfoma (NHL)'nın nadir bir formu olan primer santral sinir sistemi (SSS) lenfoması, agresif ekstranodal SSS'nin yüksek gradlı B hücre neoplazmı olarak tanımlanır. SSS lenfoma insidansı son yıllarda giderek artmaktadır. Genel olarak kötü prognoza sahiptir. Bu çalışmada; primer SSS lenfoması tanısı alan hastaların klinik, patolojik, immünhistokimyasal ve radyolojik özellikleri literatür eşliğinde değerlendirmesi amaçlanmıştır.

Gereç ve yöntem: Mayıs 2011 ile Ocak 2017 tarihleri arasında primer SSS lenfoma tanısı patolojik olarak doğrulanmış 10 hasta retrospektif olarak incelendi.

Bulgular: SSS lenfomalı 10 hastanın 7 (\%70)'si kadın 3 (\%30)'ü erkekti. Tüm hastaların tanı konulduğundaki ortalama yaşları 59,1 113,98 idi. En sık yerleşim yeri; 8 hastada (\%80) bazal ganglia bölgesi olup, 3 hastanın (\%30) çoklu intrakranyal kitleleri vardı. 8 hastada (\%80) sterotaksik beyin biyopsisi, 2 hastada (\%20) kranyotomi le tümör rezeksiyonu yapıldı. Tümü non-Hodgkin B hücreli lenfoma olan hastaların 10 'u da (\%100) diffüz büyük B hücreli lenfoma idi. Tüm vakalarda CD20 için diffüz ve kuvvetli pozitiflik görüldü. İmmün yetmezlik hiçbir hastada yoktu.

Sonuç: Kötü prognoza sahip olan primer SSS lenfoması sıklıkla 55 yaşın üzerinde görülür. Diffüz büyük B-hücreli lenfoma en sık alt tip olup bazal ganglia bölgesi en sık yerleşim yeridir.

Anahtar kelimeler: Non-Hodgkin lenfoma, santral sinir sistemi, primer lenfoma, büyük B hücreli lenfoma.

Özdemir Ovalıoğlu A, Canaz G, Taçyıldız AE, Uysal ML, Ovalıoğlu TC. Primer santral sinir sistemi lenfomaları: 10 vakanın retrospektif analizi. Pam Tıp Derg 2020;13:605-611.

\begin{abstract}
Purpose: Primary central nervous system (CNS) lymphoma, a rare form of non-Hodgkin's lymphoma (NHL), is defined as high-grade B cell neoplasm of aggressive extranodal CNS. The incidence of CNS lymphoma has been increasing in recent years. In general, it has a poor prognosis. The aim of this study is to evaluate the clinical, pathological, immunohistochemical and radiological features of patients with primary CNS lymphoma in the light of literature.

Materials and methods: Between May 2011 and January 2017, 10 patients with pathologic confirmation of primary CNS lymphoma were retrospectively reviewed.

Results: Of 10 patients with CNS lymphoma, 7 (70\%) were female and $3(30 \%)$ were male. The mean age of all patients at diagnosis was $59.1 \pm 13.98$ years. The most common settlements; eight patients $(80 \%)$ had basal ganglia and 3 patients $(30 \%)$ had multiple intracranial masses. Sterotaxic brain biopsy was performed in 8 patients $(80 \%)$ and tumor resection was performed by craniotomy in 2 patients $(20 \%)$. All of the patients with non-Hodgkin B cell lymphoma had diffuse large B cell lymphoma in 10 (100\%). All cases had diffuse and strong positivity for CD20. None of the patients had immunodeficiency.

Conclusion: Primary CNS lymphoma with a poor prognosis is frequently seen over 55 years of age. Diffuse large B-cell lymphoma is the most common subtype and basal ganglia is the most common site.
\end{abstract}

Key words: Non-Hodgkin lymphoma, large B cell lymphoma, central nervous system, primary lymphoma.

Ozdemir Ovalioglu A, Canaz G, Taçyildiz AE, Uysal ML, Ovalioglu TC. Primary central nervous system lymphomas: retrospective analysis of 10 cases. Pam Med J 2020;13:605-611.

Ayşegül Özdemir OVALıOĞLU, Uzm. Dr. Bakırköy Prof. Dr. Mazhar Osman Ruh ve Sinir Hastalıkları Hastanesi, Beyin Cerrahisi Kliniği, İstanbul, Türkiye, e-posta: draysegulozdemir@gmail.com (orcid.org/0000-0003-2292-3132)

Gökhan CANAZ, Uzm. Dr. İstanbul Arnavutköy Devlet Hastanesi, Beyin ve Sinir Cerrahisi Kliniği İstanbul, Türkiye, e-posta: gokhancanaz@ gmail.com (orcid.org/0000-0003-0658-9306) (Sorumlu Yazar)

Abdullah Emre TAÇYILDIZ, Uzm. Dr. Karabük Üniversitesi Eğitim ve Araştırma Hastanesi, Beyin Cerrahisi Kliniği, Karabük, Türkiye, e-posta: abdullahemretacyildiz@gmail.com (orcid.org/0000-0001-5806-243X)

Mustafa Levent Uysal, Uzm. Dr. Bakırköy Prof. Dr. Mazhar Osman Ruh ve Sinir Hastalıkları Hastanesi, Beyin Cerrahisi Kliniği, İstanbul, Türkiye, e-posta: mluysal@gmail.com (orcid.org/0000-0001-5562-6041)

Talat Cem Ovalığlu, Uzm. Dr. Bakırköy Prof. Dr. Mazhar Osman Ruh ve Sinir Hastalıkları Hastanesi, Beyin Cerrahisi Kliniği, İstanbul, Türkiye, e-posta: talatcem@hotmail.com (orcid.org/0000-0003-1682-9641) 


\section{Giriş}

SSS lenfoması primer veya sistemik lenfomanın SSS tutulumuna sekonder olabilir. Primer tip daha nadir görülmektedir. Tanı esnasında SSS haricinde vücudun başka bir yerinde saptanmayan ve SSS'den (beyin parenkimi, spinal kord, leptomeninksler veya göz) köken alanlar primer olarak adlandırılır [1]. Non-Hodgkin lenfoma (NHL)'nın nadir bir formu olan primer santral sinir sistemi (SSS) lenfoması, agresif ekstranodal yüksek gradlı B hücre neoplazmıdır. Primer SSS lenfomaları; sıklıkla büyük veya immünoblastik tipte malign hücrelerdir.

Primer SSS lenfomasının tanısı sıklıkla stereotaktik biyopsi ile konur [2-8]. Bu tümörlerin günümüzdeki tedavisi kemoterapi ve radyoterapidir [2, 3, 5-9]. İmmünoterapi, hedeflenmiş terapi veya kök hücre transplantasyonu gibi birtakım yeni tedavi stratejileri geliştirilmektedir [3, 5-7, 10].

SSS lenfoma insidansı son yıllarda giderek artmaktadır ve genel olarak kötü prognoza sahiptir. SSS lenfomaları ayırıcı tanısında multifokal veya multisentrik gliomlar, multipl skleroz ve enflamasyon düşünülmelidir. Tedavi edilmeyen hastalarda yaşam süresinin kısa olmasından dolayı olabilecek en kısa sürede tedaviye başlanması gerekir [11]. Bu çalışmada; primer SSS lenfoması bulunan hastaların klinik, patolojik, immünhistokimyasal ve radyolojik özelliklerini literatür eşliğinde sunmayı amaçladık.

\section{Gereç ve yöntem}

Kliniğimizde Mayıs 2011 ile Ocak 2017 tarihleri arasında histopatolojik olarak primer SSS Ienfoması tanısı konulan ardışık 10 hasta retrospektif araştırıldı. Demografik, klinik, laboratuvar, radyolojik ve patolojik özellikleri değerlendirildi. Hastaların sistemik muayeneleri, lenf nodu taraması ve tüm vücut pozitron emisyon tomografi (PET)görüntüleri incelenerek sistemik lenfoması olmayanlar çalışmaya dahil edildi. Postoperatif ilk 24 saat içinde bilgisayarlı tomografi (BT) ve/veya manyetik rezonans (MR) görüntülemeleri çekildi. Bütün hastaların aydınlatılmıs bilgi onam formu bulunmaktaydı. Etik Kurul onayı, Bakırköy Prof. Dr. Mazhar Osman Ruh ve Sinir Hastalıkları Hastanesi Etik
Kurulu'ndan alınmıştır. İstatiktiksel analizler SPSS Statistics 24.0 (SPSS Inc, Chicago, IL, USA) programında yapıldı.

\section{Bulgular}

Primer SSS lenfomalı 10 hastanın yaşları 26 ile 77 (ortalama 59.1 \pm 13.98 ) arasında değişmekteydi. 10 hastanın 7'si kadın (\%70), 3'ü erkek (\%30) idi. Klinik belirtiler arasında en sık baş ağrısı bulunmaktaydı. Bir hastada tip 2 diyabet, bir hastada hipertansiyon, bir hastada ötiroid guatr olup bir hastada geçirilmiş koroner by-pass ve bir hastada uyuşturucu kullanım öyküsü bulunmaktaydı. Her hastanın preoperatif BT ve kontrastlı MR görüntülemeleri dikkatlice incelendi. En sık yerleşim yeri; 8 hastada $(\% 80)$ bazal çekirdek bölgesi olup, 3 hastanın (\%30) çoklu intrakranyal kitleleri vardı. Multipl kitleleri olan hastaların birinde bilateral talamusta, ponsta ve mezensefalonda lezyonlar izlendi. Diğerinde bilateral bazal çekirdeklerde, üçüncü hastada ise talamus ve bilateral serebellar hemisferlerde lezyonlar görüldü. BT'de izoveya hiperdens, MR'da ise T2 ve FLAIR'da hiperintens görüntü veren bu lezyonların tümünde belirgin kontrast tutulumu gözlendi. Lezyonların çevresindeki ödem kitleden iyi ayırt edilebilmekteydi. Baş ağrısı en sık görülen semptom $(5 / 10, \% 50)$ olup, fokal nörolojik defisit $(3 / 10, \% 30)$, konuşma bozukluğu $(2 / 10$, $\% 20)$, yürüme güçlüğü $(2 / 10, \% 20)$, bilinç değişiklikleri $(2 / 10, \% 20)$ ve unutkanlık $(2 / 10$, $\% 10)$ diğer bulgulardı. Hastaların şikayetlerinin süresi bir hafta ile 11 ay arasında (ort. 4,2 ay) değişmekteydi. 8 hastada $(\% 80)$ stereotaktik beyin biyopsisi, 2 hastada (\%20) kranyotomi le tümör rezeksiyonu yapılmıştı (Resim 1-3). Illk 24 saat içinde çekilen postoperatif BT ve/ veya $M R$ görüntülerde lezyonların tümünde hedeflenen bölgelerden doku çıkarıldığı görüldü. Histopatolojik olarak tüm primer SSS lenfomalı hastalarda Non-Hodgkin lenfoma saptandıdğı görüldü. Subtiplere bakıldığında hepsi (\%100) diffüz büyük $B$ hücreli lenfoma idi. Tüm vakalarda CD20 için diffüz ve kuvvetli pozitiflik mevuct idi (Tablo 1). Patolojik tanıları belirlendikten sonra hastalar ek tedavilerinin düzenlenmesi amacıyla dış merkez onkoloji kliniklerine yönlendirilmişti. Postoperatif her hastada steroid tedavisi ve kemoterapi verilirken, bunlara ek olarak iki hastada radyoterapi de uygulandığı görüldü. İmmün yetmezlik hiçbir hastada yoktu. 
Hastaların takip süresi 6-23 ay (ort. 12,2 ay) arasında değişmekteydi. Ameliyat sonrası 3. ay kontrolünde hastaların 9'unda (9/10, \%90) şikayetlerin düzeldiği, birinde (1/10, $\% 10)$ ise şiddetli baş ağrısının azalarak devam ettiği öğrenildi. 8 hastada $(8 / 10, \% 80)$ tümörün kaybolduğu, 2 hastada (2/10, \%20) ise tümör boyutlarında belirgin azalma olduğu görüldü. Takiplerde hastaların 8'inde rekürrens gelişirken, bu hastaların 5'i hayatını kaybetti, 2 hasta halen yaşamakta olup bir hastaya 6 . aydan sonra ulaşılamadı.

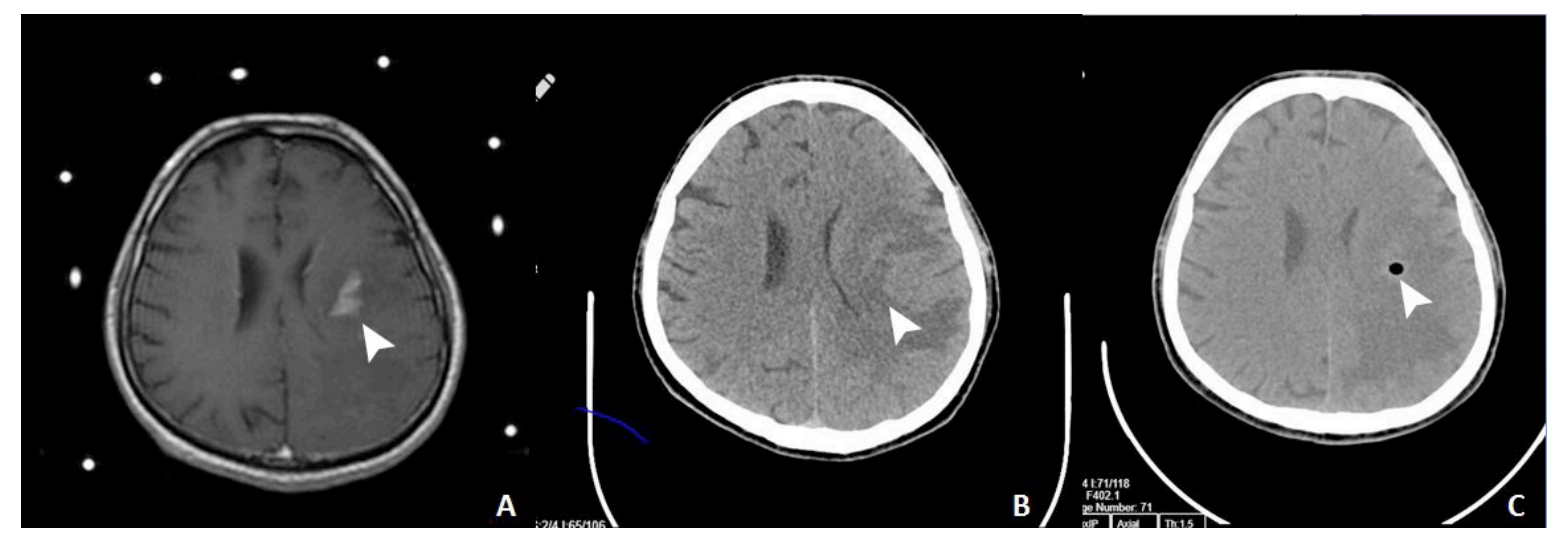

Resim 1. Sol talamik yerleşimli kitle

A: Preop stereotaksik MR görüntüsü. B: Preop BT görüntüsü. C: Stereotaksik biyopsi sonrası kontrol BT görüntüsü

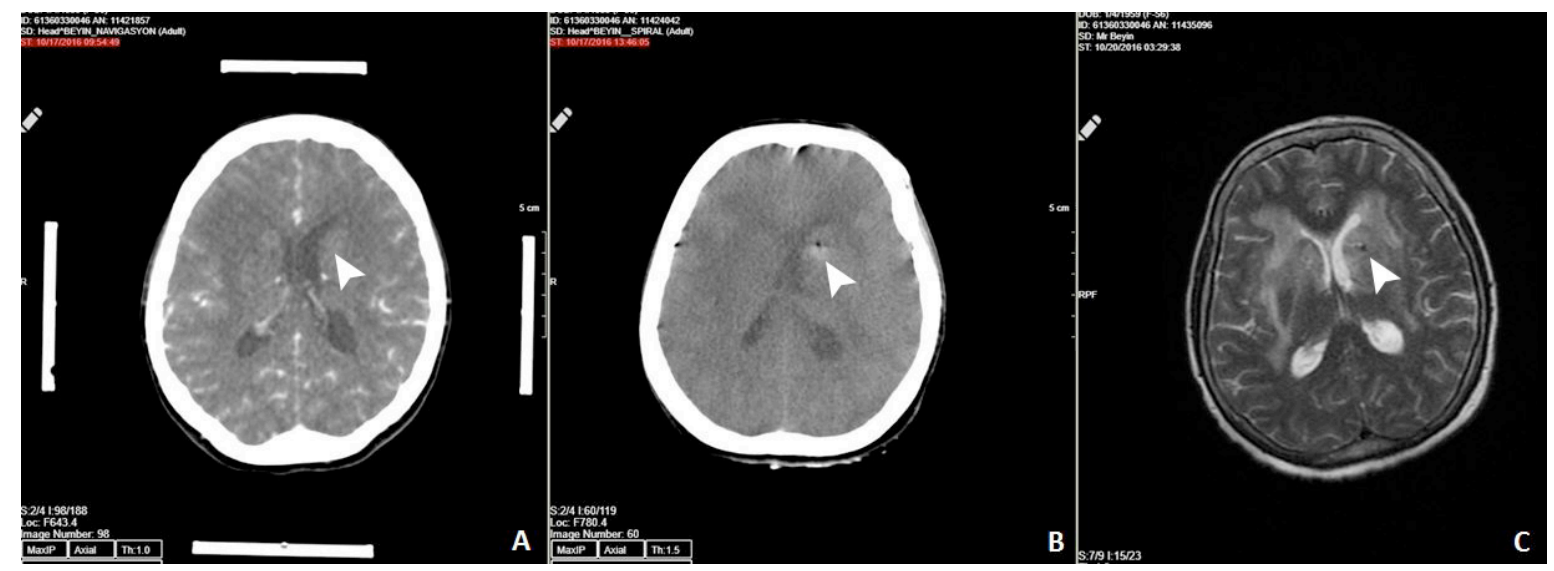

Resim 2. Sol anterior talamus yerleşimli kitle

A: Preop stereotaksik kontrastlı BT görüntüsü, B: Biyopsi sonrası kontrol BT görüntüsü, C: Postop kontrol MR görüntüsü 

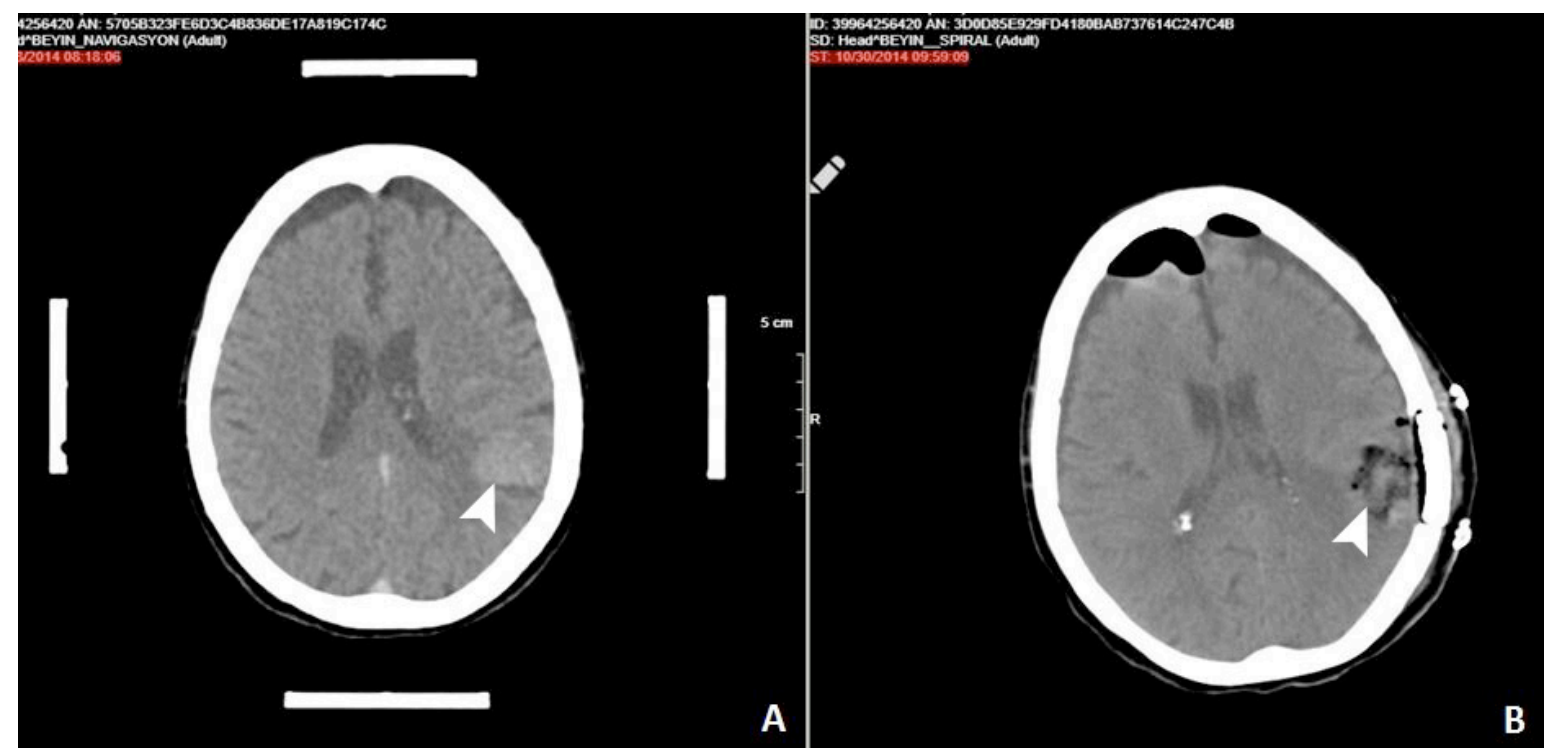

Resim 3. Sol pariteal bölge yerleşimli kitle A: Preop stereotaksik kontrastsız BT görüntüsü, B: Stereotaksik eksizyon sonrası postop kontrol BT görüntüsü

\section{Tartışma}

Primer SSS lenfoması; tüm SSS tümörlerinin $\% 1-5$ 'i ve non-Hodgkin lenfomaların \%2-3'ü kadarını oluşturmaktadır [12, 13]. Sekonder olanlara primer SSS lenfomasından daha sık rastlanır. Hodgkin lenfomada ise SSS tutulumu oldukça nadirdir. Diffüz büyük B hücreli lenfoma alt tipi tüm primer SSS lenfomaların \%90'ından fazlasını teşkil eder. Burkitt lenfoma, T hücreli lenfoma ve düşük gradlı lenfomalar ise daha seyrektir. CD20 pozitiflik ve CD138 negatiflik diferansiasyonu bu tip tümör hücrelerinin spesifik immünhistokimyasal belirteçleridir [8]. Bizim çalışmamızda yer alan primer SSS lenfomalı hastalarımızın hepsinde non-Hodgkin lenfomanın subtipi diffüz büyük $B$ hücreli lenfoma saptandı. Yine diğer çalışmalardaki ile uyumlu olarak tüm vakalarımızda CD20 için diffüz ve kuvvetli pozitiflik görüldü.

SSS lenfoma insidansı son yıllarda giderek artmaktadır [8]. Hastaneye yatışlarının artması, tanı tekniklerinde teknolojik gelişmeler, HIV enfeksiyonu insidansının artışı, organ transplantasyonu sonrası Kazanılmış Bağışıklık Yetmezliği Sendromu (AIDS) olan hastalarda gelişen tümörlerin \%10 kadarı non-Hodgkin lenfomalar olup bunların da \%10-15 kadarını primer SSS lenfoması oluşturur [14, 15]. Yapılan laboratuvar incelemelerinde hastalarımızın hiçbirinde AIDS veya bir immün yetmezlik saptanmamıştır.

SSS lenfoma insidansı son yıllarda giderek artmaktadır [8]. Primer SSS Ienfomalı hastaların büyük çoğunluğu erkektir ve tanı aldıklarında ortalama 60 yaş civarındadır, etnik gruplar arasında bir farklılık bulunmamaktadır [2, 4, 7-9]. Çalışmamızda 26 yaşındaki erkek hasta dışındaki tüm hastalarımız 6 . dekat ve üzerinde bulunmaktaydı. Klinik belirtiler, lezyonların yerleşim yeri ve sayısı (tek veya çok) gibi çeşitli faktörlere bağlı olarak değişir. Çalışmalarda primer SSS lenfomalı hastaların \%34 kadarında multipl lezyonlar olduğu ve bunların sıklıkla frontal lobda yerleştiği görülmüştür $[2,4,6$, 8]. Bunun yanısıra; korpus kallozum, bazal çekirdek, periventriküler bölge, beyin sapı veya serebellum gibi derin beyin dokusu tutulumu primer SSS lenfomalı hastalarda $\% 40$ oranında görülür $[2,3,5,6,8,10]$.

Tanı en sık stereotaktik biyopsi ile konulur [2-8]. 


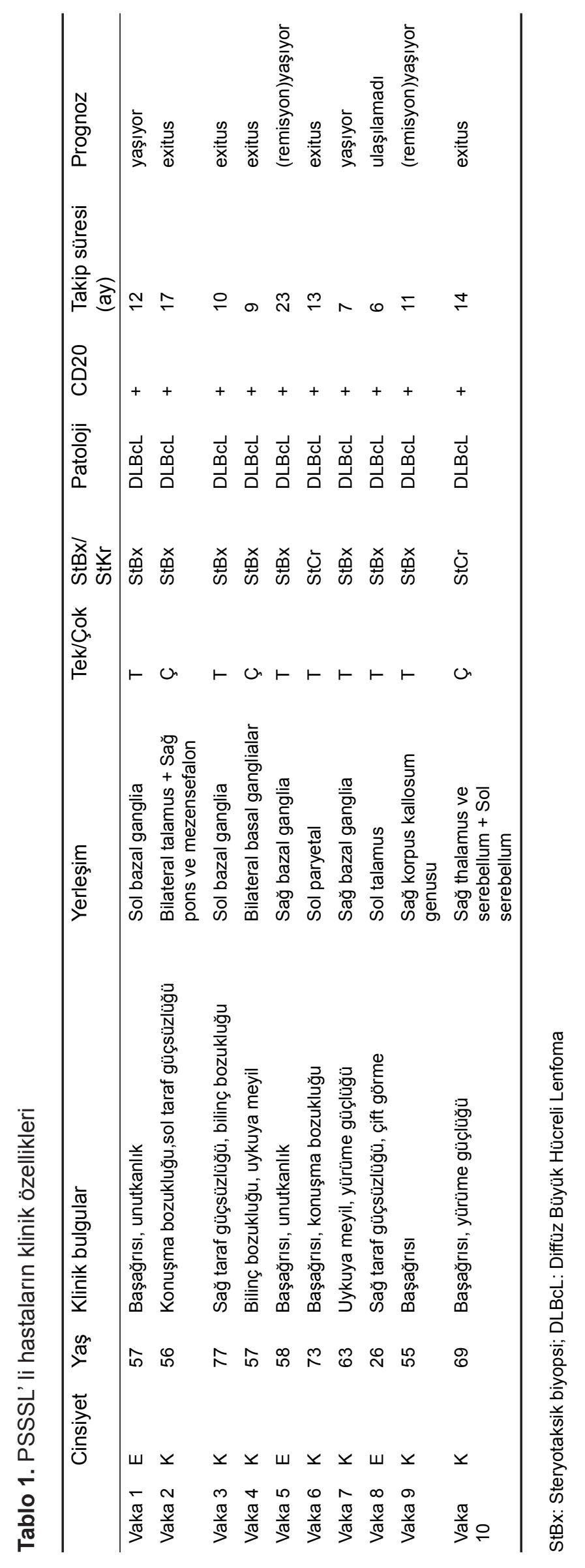


SS lenfoması nispeten spesifik radyolojik görüntülere sahiptir. Tümör kitlesi, BT'de belirgin olarak yüksek dansitede (nadiren çevresindeki doku ile aynı dansitede olabilir) olup düzgün kontrast tutulumu gösterir. MR görüntülemede tipik olarak T1'de izo veya hipointens, T2'de ve FLAIR'de hiperintens özelliktedir. Korpus kallozum yerleşimli lezyonlar; kontrastlı MR'da yumruk gibi, alev şeklinde veya kelebek görüntüsünde belirgin ve düzgün tutulum gösterir $[3-6,10]$. SSS lenfomaları ayırıcı tanısında multifokal veya multisentrik gliomlar, metastatik tümörler, multipl skleroz ve enflamasyon düşünülmelidir. Primer SSS lenfoması kötü prognozlu oldukça agresif bir tümör olup tanıdan itibaren ortalama yaşam süresi 9 ay civarındadır [7]. Tanı ve tedavi süreçleri; primer SSS lenfomasının yüksek malign davranışlı ve kötü prognozlu olması nedeniyle oldukça zorludur ve mücadele gerektirmektedir [2, 7, 8]. Tedavi edilmeyen hastalarda yaşam süresinin kısa olmasından dolayı olabilecek en kısa sürede tedaviye başlanması gerekir [11]. Diğer beyin tümörleriyle kıyaslandığında; yeni tanı konmuş primer SSS lenfomasının tedavisinde rezeksiyon endikasyonu olmayıp radyasyon ve/veya kemoterapi önerilmektedir $[16,17]$. İmmünoterapi, hedeflenmiş terapi veya kök hücre transplantasyonu gibi yeni tedavi stratejileri de umut vericidir $[3,5-7,10]$.

Çalışmamızın zayıf yönlerinden biri şudur $\mathrm{ki}$, hastaların cerrahi sonrası tedavileri farklı onkoloji kliniklerinde devam ettiği için kemoterapi rejimleri ve radyoterapi endikasyonlarının geriye dönük değerlendirilmesi mümkün olmadı; bizim takiplerimizde ise iki hastanın birinin 6 aylık takipler sonunda exitus olduğunu, diğerinin 9 aylık takiplerinde hayatta olduğunu gördük.

Sonuç olarak, primer SSS lenfoma sıklıkla 55 yaşın üzerindeki erişkinlerde görülür. Diffüz büyük $B$ hücreli lenfomalar en baskın alt tip olup en sık bazal çekirdek bölgesinde yerleşir.

Çıkar ilişkisi: Yazarlar çıkar ilişkisi olmadığını beyan eder.

\section{Kaynaklar}

1. Wang CC, Carnevale J, Rubenstein JL. Progress in central nervous system lymphomas. $\mathrm{Br}$ JHaematol 2014;166:311-325. https://doi.org/10.1111/bjh.12938

2. Bhagavathi S, Wilson JD. Primary central nervous system lymphoma. Arch Pathol Lab Med 2008;132:1830-1834. https://doi.org/10.1043/15432165-132.11.1830
3. Brastianos PK, Batchelor TT. Primary central nervous system lymphoma: overview of current treatment strategies. Hematol/Oncol Clin North Am 2012;26:897916. https://doi.org/10.1016/j.hoc.2012.05.003

4. Haque S, Law M, Abrey LE, Young RJ. Imaging of lymphoma of the central nervous system, spine, and orbit. Radiol Clin N Am 2008;46:339-361. https://doi. org/10.1016/j.rcl.2008.04.003

5. Nayak L, Batchelor TT. Recent advances in treatment of primary central nervous system lymphoma. Curr Treat Options in Oncol 2013;14:539-552. https://doi. org/10.1007/s11864-013-0252-6

6. Perini GF, Campregher PV, Santos FP, Hamerschlak N. Primary central nervous system lymphoma: what a neurologist/neurosurgeon should know? Arq de Neuro-Psiquiatr 2013;71:254-257. https://doi. org/10.1590/0004-282x20130011

7. Phillips EH, Fox CKP, Cwynarski K. Primary CNS lymphoma. Curr Hematol Malignancy Rep 2014;9:243253. https://doi.org/10.1007/s11899-014-0217-2

8. Rubenstein J, Ferreri AJ, Pittaluga S. Primary lymphoma of the central nervous system: epidemiology, pathology and current approaches to diagnosis, prognosis and treatment. Leukemia\&Lymphoma 2008;49:43-51. https://doi.org/10.1080/10428190802311441

9. Yoon JH, Kang HJ, Kim H, et al. Successful treatment of primary central nervous system lymphoma without irradiation in children: single center experience. J Korean Med Sci 2012;27:1378-1384. https://doi. org/10.3346/jkms.2012.27.11.1378

10. Gallop Evans E. Primary central nervous system lymphoma. Clin Oncol 2012;24:329-338. https://doi. org/10.1016/j.clon.2012.02.009

11. Liu HL, Liu T, Ma C, Zhao Y, Zhou Y. Clinical characteristics and prognosis of 20 cases of primary central nervous system lymphoma. Zhongguo Shi Yan Xue Ye Xue Za Zhi 2015;23:111-118. https://doi. org/10.7534/j.issn.1009-2137.2015.01.021

12. Bathla G, Hegde A. Lymphomatous involvement of the central nervous system. Clin Radiol 2016;71:602-609. https://doi.org/10.1016/j.crad.2016.02.006

13. Olson JE, Janney CA, Rao RD, et al. The continuing increase in the incidence of primary central nervous system non-Hodgkin lymphoma: a surveillance, epidemiology, and end results analysis. Cancer 2002;95:1504-1510. https://doi.org/10.1002/ cncr.10851

14. Gasser O, Bihl FK, Wolbers M, et al. HIV patients developing primary CNS lymphoma lack EBV-specific CD4+ $T$ cell function irrespective of absolute CD4+ T cell counts. PLoS Med 2007;4:96. https://doi. org/10.1371/journal.pmed.0040096 
15. Gopal S, Patel MR, Yanik EL, et al. Temporal trends in presentation and survival for HIV-associated lymphoma in the antiretroviral therapy era. J Natl Cancer Inst 2013;105:1221-1229. https://doi.org/10.1093/jnci/ djt158

16. Beiko J, Suki D, Hess KR, et al. IDH1 mutant malignant astrocytomas are more amenable to surgical resection and have a survival benefit associated with maximal surgical resection. Neuro Oncol 2014;16:81-91. https:// doi.org/10.1093/neuonc/not159

17. Weller M, Martus P, Roth P, Thiel E, Korfel A, German PSG. Surgery for primary CNS lymphoma? Challenging a paradigm. Neuro Oncol 2012;14:1481-1484. https:// doi.org/10.1093/neuonc/nos159

Etik kurul onayı: Bakırköy Prof. Dr. Mazhar Osman Ruh ve Sinir Hastalıkları Hastanesi Etik Kurulu'ndan, 29.01.2020 tarih ve 3030 sayı ile onay alınmıştır.

\section{Yazarların makaleye olan katkıları}

A.O., T.O. çalışmanın ana fikrini ve hipotezini kurgulamışlardır. A.O., G.C., A.T. teoriyi geliştirmiş ve materyel metod bölümünü düzenlemişlerdir. Sonuçlar kısmınındaki verilerin değerlendirmesini G.C., A.T. yapmışlardır. Makalenin tartışma bölümü A.O., M.U. tarafından yazılmış, M.U., T.O. gözden geçirip gerekli düzeltmeleri yapmış ve onaylamıştır. Ayrıca tüm yazarlar çalışmanın tamamını tartışmış ve son halini onaylamıştır. 